\title{
La Ley de Identidad de Género en Argentina y su efectivo cumplimiento por parte de los financiadores de la salud
}

\author{
The Law of Gender Identity in Argentina and their effective enforcement by health \\ funders
}

A Lei de Identidade de Gênero na Argentina e sua aplicação efectiva pelos financiadores de saúde

RESUMEN: Argentina sancionó en el año 2012 la llamada Ley de Identidad de Género tomando como precedentes: la salud sexual como derecho humano, los Principios de Yogyakarta, y la jurisprudencia nacional y extranjera. La ley se compadece con todos esos precedentes y se dictó en el marco de una corriente enrolada en la búsqueda por despatologizar la identidad trans y desjudicializar los posibles conflictos relacionados con el cambio de sexo. Sin embargo, la norma llevada a la práctica ha sido desvirtuada por la reglamentación del Organismo que tiene a su cargo el contralor de las Obras Sociales que exige, entre otras cosas que, para recurrir a los tratamientos hormonales o quirúrgicos de cambio de sexo, se compruebe fehacientemente la existencia de "disforia de género", contraviniendo de esa forma el espíritu de la Ley. Se requiere entonces, de la urgente adecuación de la norma de inferior jerarquía a la de jerarquía superior en la pirámide constitucional.

Palabras-llave: Salud sexual. Sexo y Género. Disforia de Género.

ABSTRACT: Argentina sanctioned in 2012 the law called Gender Identity Law taking as precedents: sexual health as a human right, the Yogyakarta Principles, and domestic and foreign jurisprudence. The law sympathizes with all those precedents and was issued under a stream enrolled in the search for identity trans, to end with potential conflicts related to sex change. However, the rule put into practice has been undermined by the regulations of the Agency that is responsible for the control of Social Security that required to use hormonal and surgical sex reassignment treatments, the proof of the existence of "gender dysphoria", thus contravening the spirit of the law. It then requires the urgent adaptation of the rules of inferior rank to the top rank in the constitutional pyramid.

Keywords: Sexual Health. Sex and Gender. Gender Dysphoria.

\footnotetext{
1 Abogada, Posgrado en Derecho de la Salud, en Administración y Gerenciamiento en Servicios de Salud y en Auditoría Estratégica en Servicios de Salud. Diplomada en Psiquiatría Forense para Abogados.Presidenta de la Fundación Fundaleis-Altos Estudios e Investigación en Salud. Presidenta de la Comisión de Derecho Sanitario de la Asociación de Abogados de Buenos Aires y representante ante la Federación Argentina de Colegios de Abogados. Directora del Instituto de Derecho Sanitario del Colegio Público de Abogados de la Capital Federal. Asesora Legal en la Gerencia de Asuntos Jurídicos de la Superintendencia de Servicios de Salud. Productora y conductora del programa radial "Salud y Derechos". Autora del libro "Judicialización de la Salud, métodos alternativos para resolver los conflictos", co-autora del libro "Derecho Sanitario y Régimen Jurídico del Medicamento" y de artículos sobre la materia publicados a nivel nacional e internacional.
} 
RESUMO: A Argentina sancionou em 2012 a chamada Lei de Identidade de Gênero tomando como precedentes: saúde sexual como um direito humano, os Princípios de Yogyakarta, e a jurisprudência nacional e estrangeira. A lei se solidariza com todos estes precedentes e foi discutida e sancionada sob o marco da busca de identidade, despatologização trans e desjudicialização de conflitos potenciais relacionados com a mudança de sexo. No entanto, a regra posta em prática tem sido prejudicada pelos regulamentos da agência que é responsável pela controladoria do trabalho social que exige, nomeadamente, que recorrer a tratamentos hormonais ou cirúrgica de mudança de sexo é verificar de forma confiável a "disforia de gênero", contrariando assim o espírito da lei. Requer ainda a adaptação urgente das regras de classificação inferior ao topo da pirâmide hierarquia constitucional.

Palavras-chave: Saúde sexual. Sexo e Género. Disforia de Gênero.

\section{Introducción}

Argentina sancionó el 9/05/2012 (1), la Ley oㅡ 26.743 que establece el derecho a la identidad de género de las personas. La norma define como identidad de sexo a:

... la vivencia interna e individual del género tal como cada persona la siente, la cual puede corresponder 0 no con el sexo asignado al momento del nacimiento, incluyendo la vivencia personal del cuerpo. Esto puede involucrar la modificación de la apariencia o la función corporal a través de medios farmacológicos, quirúrgicos o de otra índole, siempre que ello sea libremente escogido. También incluye otras expresiones de género, como la vestimenta, el modo de hablar y los modales $(1)^{2}$..

Asimismo, otorga el derecho a solicitar la rectificación registral del sexo y el cambio del nombre y de la imagen, cuando no coincidan con la identidad de sexo autopercibida. Dispone el derecho al libre desarrollo personal garantizando la posibilidad de llevar a cabo métodos hormonales o quirúrgicos para efectuar el cambio de sexo, con el sólo consentimiento de la persona.

Finalmente, ordena respetar la identidad de género adoptada, garantizándoles a las personas un trato digno y respetuoso.

El antecedente inmediato de esta norma a nivel local, es el fallo ALITT de la Corte Suprema de Justicia de la Nación del año 2006³. La Inspección General de Justicia, le había denegado la personería jurídica a la Asociación Lucha por la Identidad TravestiTransexual (ALITT), por considerar que no cumplía con el objeto de 'bien común' exigido

\footnotetext{
2 Art. 2 Ley № 26.743/2012

3 CSJN "Asociación Lucha por la Identidad Travesti-Transexual c/ Inspección General de Justicia" $21 / 11 / 2006$
} 
por el art. 33 del Código Civil de la Nación vigente en ese momento. En primera y segunda instancia del proceso llevado a cabo ante los tribunales, se confirmó la denegatoria con fundamentos en el citado artículo del Código Civil y con el argumento de que los objetivos de la Asociación sólo representaban el interés individual y un interés particular para los integrantes de la misma.

A su vez ALITT había argumentado que tal decisión llevaba implícita una actitud discriminatoria y prejuiciosa relacionada con la condición sexual de los asociados, y alegó que otros grupos como la Comunidad Homosexual Argentina, habían obtenido su personería jurídica en idénticas condiciones.

La Corte Suprema de Justicia de la Nación al resolver el caso, acordó la personería jurídica a ALITT haciendo una interpretación del 'bien común' conforme a un estado pluralista e inclusivo. Pero lo más importante es que por primera vez, el Estado argentino representado por su Máximo Tribunal de Justicia, reconoció los sufrimientos y las injusticias sufridas por parte de las minorías sexuales:

...16) Que no es posible ignorar los prejuicios existentes respecto de las minorías sexuales, que reconocen antecedentes históricos universales con terribles consecuencias genocidas, basadas en ideologías racistas y falsas afirmaciones a las que no fue ajeno nuestro país, como tampoco actuales persecuciones de similar carácter en buena parte del mundo, y que han dado lugar a un creciente movimiento mundial de reclamo de derechos que hacen a la dignidad de la persona y al respeto elemental a la autonomía de la conciencia.

17) Que tampoco debe ignorarse que personas pertenecientes a la minoría a que se refiere la asociación apelante no sólo sufren discriminación social, sino que también han sido victimizadas de modo gravísimo, a través de malos tratos, apremios, violaciones y agresiones, e inclusive con homicidios.

Como resultado de los prejuicios y la discriminación que les priva de fuentes de trabajo, tales personas se encuentran prácticamente condenadas a condiciones de marginación, que se agravan en los numerosos casos de pertenencia a los sectores más desfavorecidos de la población, con consecuencias nefastas para su calidad de vida y su salud, registrando altas tasas de mortalidad, todo lo cual se encuentra verificado en investigaciones de campo.

18) Que resulta prácticamente imposible negar propósitos de bien común a una asociación que procura rescatar de la marginalidad social a un grupo de personas y fomentar la elevación de su calidad de vida, de sus niveles de salud física y mental, evitar la difusión de dolencias infecciosas, prolongarles la vida, abrir proyectos para que la única opción de vida deje de hallarse en los bordes de la legalidad o en el campo de arbitrariedad controladora y, en definitiva, evitar muertes, violencia y enfermedad. Ello implicaría desconocer el principio con arreglo al cual el bien colectivo tiene 
una esencia pluralista, pues sostener que ideales como el acceso a la salud, educación, trabajo, vivienda y beneficios sociales de determinados grupos, así como propender a la no discriminación, es sólo un beneficio propio de los miembros de esa agrupación, importa olvidar que esas prerrogativas son propósitos que hacen al interés del conjunto social como objetivo esencial y razón de ser del Estado de cimentar una sociedad democrática, al amparo de los arts. 14 y 16 de la Constitución Nacional y de los tratados internacionales incorporados en su art. 75 , inc. $22 \ldots$

Pero el antecedente más importante a nivel internacional, lo constituyen los llamados "Principios de Yogyakarta"4 referidos a la aplicación de la legislación internacional de derechos humanos en relación con la orientación sexual e identidad de género.

Los Principios fueron desarrollados y adoptados por unanimidad por un distinguido grupo de expertos en derechos humanos de distintas regiones y diversa formación, entre ellos: jueces, académicos, un ex Alto Comisionado de Derechos Humanos de la ONU, miembros de órganos de los tratados, ONGs y otros. Un evento clave para desarrollar los Principios fue un seminario internacional que se llevó a cabo en Yogyakarta, Indonesia, en la Universidad de Gadjah Mada del 6 al 9 de noviembre del 2006, y en donde participaron muchos de los expertos en leyes mencionados.

Se refieren a una amplia gama de derechos humanos y cómo se aplican en cuestiones de orientación sexual e identidad de género. Se incluyen entre otros: violencia y tortura, acceso a la justicia, privacidad, no discriminación, los derechos de libertad de expresión y reunión, empleo, salud, educación, cuestiones de migración y refugiados, participación pública y una variedad de otros derechos.

Otro antecedente a tener en cuenta lo constituyó el fallo de la Corte Interamericana de Derechos Humanos en el caso "Atala Riffo y niñas vs. Chile" 5 del 24/02/2012. El caso se relaciona con el proceso de custodia interpuesto ante los tribunales chilenos por el padre de dos niñas en contra de su mamá, la Sra. Karen Atala Riffo, por considerar que su convivencia con una pareja del mismo sexo produciría un daño a sus hijas. En la sentencia la Corte declaró a Chile responsable internacionalmente por haber vulnerado el derecho a la igualdad y a la no discriminación y el derecho a la vida privada, entre otros. Consideró que un posible estigma social debido a la orientación sexual de la

\footnotetext{
${ }^{4}$ www.yogyakartaprinciples.org/principles sp.pdf

5 ww.corteidh.or.cr/docs/casos/articulos/seriec_239_esp.pdf
} 
madre no puede considerarse un 'daño' valido a los efectos de la determinación del interés superior del niño.

También señaló la Corte que no se encuentra determinado un concepto cerrado de familia, ni mucho menos se define y protege sólo un modelo 'tradicional' de la misma. El concepto de vida familiar no está reducido únicamente al matrimonio y debe abarcar otros lazos familiares de hecho donde las partes tienen vida en común por fuera del matrimonio. Constató que el lenguaje utilizado por la Corte Suprema de Chile relacionado con la supuesta necesidad de las niñas de crecer en una 'familia estructurada normalmente y apreciada en su medio social', y no en una 'familia excepcional', reflejaba una percepción limitada y estereotipada del concepto de familia que no tiene base en la Convención Americana al no existir un modelo específico de familia (la familia tradicional).

La legislación argentina, a diferencia de otras como la española o la inglesa en las que la posibilidad de cambio de sexo queda en manos del médico que debe diagnosticar que la persona posee trastorno de identidad sexual 0 disforia de género respectivamente, es clara cuando establece para la intervención médica sólo la solicitud de quien siente que le corresponde otra identidad de género. En base a esto, queda en claro que la ley argentina despatologiza a las personas trans.

¿Qué es la disforia de género? Es definida como una afección en la que se presenta un conflicto entre el sexo físico de la persona y el sexo con el cual se identifica. Es la sensación de estar en el cuerpo equivocado ${ }^{6}$ Esta patología se trata con terapia a pesar de que en 1973 la Asociación Americana de Psiquiatría eliminó la homosexualidad del Manual de Diagnóstico y Estadístico de los Trastornos Mentales (DSM) y la Organización Mundial de la Salud (OMS) la eliminó de la lista de enfermedades mentales. Pero la disforia de género permanece en el DSM-IV como trastorno de la identidad sexual.

Del art. 18 de los Principios de Yogyakarta, sin embargo, se desprende que no se trata de un trastorno cuando sostiene que:

Principio 18: Protección contra abusos médicos: Ninguna persona será obligada a someterse a ninguna forma de tratamiento, procedimiento o exámenes médicos o psicológicos, ni a permanecer confinada en un

${ }^{6}$ https://www.nlm.nih.gov/medlineplus/spanish/ency/article/001527.htm 
centro médico, con motivo de su orientación sexual o identidad de género. Con independencia de cualquier clasificación que afirme lo contrario, la orientación sexual y la identidad de género de una persona no son, en sí mismas, condiciones médicas y no deberán ser tratadas, curadas o suprimidas.

El año pasado 2015, después de largas luchas sociales a fin de lograrlo, la Ley $n^{0}$ 26.743 fue reglamentada ${ }^{7}$ en su artículo 11 y en el anexo de la reglamentación se determina que:

Se entiende por intervenciones quirúrgicas totales y parciales a las cirugías que ayuden a adecuar el cuerpo a la identidad de género autopercibida. Las mismas comprenden: Mastoplastía de aumento, Mastectomía, gluteoplastía de aumento, Orquiectomía, Penectomía, Vaginoplastía, Clitoroplastía, Vulvoplastía, Anexohisterectomía, Vaginectomía, Metoidioplastía, Escrotoplastía y Faloplastía con prótesis peneana, resultando la presente enumeración de carácter meramente enunciativo y no taxativo.

Se entiende por tratamientos hormonales integrales a aquellos que tienen por finalidad cambiar los caracteres secundarios que responden al sexo gonadal, promoviendo que la imagen se adecue al género autopercibido. Todos los productos deben estar aprobados por la Administración Nacional de Medicamentos, Alimentos y Tecnología Médica (ANMAT).

La Ley $n^{\circ} 26.743$ garantiza que los efectores del sistema de salud, ya sean estatales, privados o de obras sociales, deberán garantizar en forma permanente los derechos que la misma reconoce y todas las prestaciones de salud contempladas en el art. 11 de la reglamentación citada quedan incluidas en el Plan Médico Obligatorio, o el que lo reemplace, conforme lo determine la autoridad de aplicación.

La Superintendencia de Servicios de Salud, que es el Organismo dependiente del Ministerio de Salud de la Nación facultada para ejercer el contralor de las Obras Sociales Nacionales de las Leyes № 23.660 y № 23.661y de las Empresas de Medicina Prepaga, ha dictado la Resolución № 1561/12-S.S.Salud a fin de regular el procedimiento para la autorización de reintegros a las Obras Sociales, por las prácticas allí establecidas; reintegros que surgen del Fondo Solidario de Redistribución al que todas ellas aportan a fin de poder financiar en forma solidaria, determinados tratamientos.

\footnotetext{
7 Decreto 903/15-PEN
} 
Esta norma establece como requisitos para intervención quirúrgica en el Módulo de Cirugía de Reasignación Sexual, los siguientes:

- Disforia de género, persistente y bien documentada

- Capacidad de tomar una decisión, bien informada y dar el consentimiento de su tratamiento

- Un mínimo de 12 meses continuos de terapia hormonal apropiada para los objetivos del género del paciente (salvo que exista contraindicación del tratamiento) a fin de lograr una supresión hormonal reversible

- Un mínimo de 12 meses continuos de vida en el género sexual que sea congruente con su identidad de género

- Informe del equipo interdisciplinario donde conste el aval para la realización de la práctica hormonal, si correspondiera

A la luz de lo expuesto, esta reglamentación atenta contra el espíritu de la Ley no 26.743, a la vez que resulta inconstitucional por tratarse de una norma de inferior jerarquía constitucional que contradice abiertamente lo establecido por una norma de jerarquía superior. No sólo "patologiza" la situación de las personas trans, sino que viola su derecho a la vida privada al tener que demostrar, quien pretenda cambiar su sexo, que ha llevado por el lapso de un año al menos, una vida sexual acorde con su identidad de género. Por otra parte, en Argentina el equipo interdisciplinario es el modo de abordaje cuando estamos en presencia de un problema de salud mental ${ }^{8}$.

Asimismo, cabe agregar que la ley es clara cuando no condiciona el acceso a las intervenciones quirúrgicas a los tratamientos hormonales, como sí lo hace la Resolución Ministerial citada

\section{Conclusiones y propuestas}

El Derecho de la Salud hoy debe analizarse y aplicarse desde el punto de vista multidisciplinario. Justamente la mirada desde otras disciplinas, ha permitido darle a la salud y a la enfermedad un matiz más humano. Y no es que la medicina no lo sea, sino simplemente que el médico estará ocupado en curar o aliviar el dolor de las personas y en esa práctica, puede no tomar en cuenta otros aspectos como los derechos del

\footnotetext{
${ }^{8}$ Ver Ley № 26.657 art. 8
} 
paciente, la necesidad de mitigar la discriminación y la estigmatización que sufren en muchos casos, ya que son cuestiones que tratan otras disciplinas.

Y esas otras disciplinas como la Psicología, han permitido diferenciar el género del sexo señalando que este último es el órgano reproductor con el que nacemos en tanto que el primero es una construcción social o cultural elaborada con características que la sociedad impone a cada persona, de acuerdo con el sexo con el que nace; y esto es precisamente, lo que ha permitido que los roles de poder estuviesen exclusivamente en manos de los hombres y se avalara la concepción histórica cónyuge-dueño que permaneció vigente en nuestra legislación durante mucho tiempo.

Se hace entonces imprescindible modificar la Resolución del Organismo dependiente del Ministerio de Salud de la Nación, a fin de adecuarlo a la Ley Nacional no 26.743 que sin dudas representa uno de los mayores avances legislativos en materia de derechos personalísimos. Por ahora esta situación no ha generado conflictos debido a que, en su mayoría, las personas trans siguen siendo marginadas y siguen por lo tanto sin poder acceder a una Obra Social, por no tener un trabajo formal. Pero quienes trabajamos con temas de Derecho de la Salud, no podemos dejar de advertir esta situación que además de inconstitucional, puede generar a futuro situaciones conflictivas y de esa forma vulnerar otro de los principios ínsitos en el espíritu de la ley: la desjudicialización.

\section{Referencias}

1.Argentina. Ley n. 26.743 de 9 de mayo de 2012. Establece el derecho a la identidad de género de las personas. Buenos Aires: 9 de mayo de 2012. [Acceso en 12.dez.2015]. Disponible en: http://www.infoleg.gov.ar.

\section{Como citar este artigo:}

Cortesi MC. La Ley de Identidad de Género en Argentina y su efectivo cumplimiento por parte de los financiadores de la salud. Revista Cadernos Ibero-Americanos de Direito Sanitário. 2016 abr./jun, 5(2):177-184. 